\title{
RESEARCH
}

Open Access

\section{Baseline factors identified for the prediction of good responders in patients with end-stage diffuse coronary artery disease undergoing intracoronary CD34+ cell therapy}

Pei-Hsun Sung ${ }^{1,2}$, Hsin-Ju Chiang ${ }^{3,4}$, Yi-Chen Li ${ }^{1}$, John Y. Chiang ${ }^{5,6}$, Chi-Hsiang Chu ${ }^{7,8}$, Pei-Lin Shao ${ }^{9}$,

Fan-Yen Lee ${ }^{10,11}$, Mel S. Lee ${ }^{12^{*+}}$ and Hon-Kan Yip ${ }^{1,2,13,14,15,9^{*}+}$ (D)

\begin{abstract}
Background: Treating patients with end-stage diffuse coronary artery disease (EnD-CAD) unsuitable for coronary intervention remains a clinical challenge. They usually express refractory angina and have a high risk of mortality. Although growing data have indicated cell therapy is an alternative solution to medical or invasive therapy, there are still lacking useful markers to predict whether heart function will improve in the EnD-CAD patients who underwent circulatory-derived CD34+ cell therapy. By utilizing the baseline variables and results from our previous phase I/II clinical trials, the aim of this study tried to elucidate the variables predictive of the "good response" to CD34+ cell therapy.

Methods: This retrospective study included 38 patients in phase I clinical trial (2011-2014), and 30 patients in phase II clinical trial (2013-2017). These patients were categorized into "good responders" and "non-responders" according to their 1-year improvement of LVEF $\geq 7.0 \%$ or $<7.0 \%$ after intracoronary CD34+ cell therapy. Univariate and multivariate logistic regression models were performed to identify potential independent predictors of a good responder to cell therapy, followed by Hosmer-Lemeshow $(\mathrm{H}-\mathrm{L})$ test for goodness of fit and prediction power.

(Continued on next page)
\end{abstract}

\footnotetext{
*Correspondence: mellee@cgmh.org.tw; han.gung@msa.hinet.net

${ }^{\dagger}$ Mel S. Lee and Hon-Kan Yip have an equal contribution to correspondent author.

${ }^{12}$ Department of Orthopedics, College of Medicine, Kaohsiung Chang Gung Memorial Hospital and Chang Gung University, Kaohsiung 83301, Taiwan 'Division of Cardiology, Department of Internal Medicine, College of Medicine, Kaohsiung Chang Gung Memorial Hospital and Chang Gung University, No. 123, Ta Pei Road, Niao Sung District, Kaohsiung 83301, Taiwan Full list of author information is available at the end of the article
}

C C The Author(s). 2020 Open Access This article is licensed under a Creative Commons Attribution 4.0 International License, which permits use, sharing, adaptation, distribution and reproduction in any medium or format, as long as you give appropriate credit to the original author(s) and the source, provide a link to the Creative Commons licence, and indicate if changes were made. The images or other third party material in this article are included in the article's Creative Commons licence, unless indicated otherwise in a credit line to the material. If material is not included in the article's Creative Commons licence and your intended use is not permitted by statutory regulation or exceeds the permitted use, you will need to obtain permission directly from the copyright holder. To view a copy of this licence, visit http://creativecommons.org/licenses/by/4.0/ The Creative Commons Public Domain Dedication waiver (http://creativecommons.org/publicdomain/zero/1.0/) applies to the data made available in this article, unless otherwise stated in a credit line to the data. 
(Continued from previous page)

Results: Among baseline data, multivariate analysis demonstrated that the history of a former smoker was independently predictive of good responders $(p=0.006)$. On the other hand, male gender, the baseline Canadian Cardiovascular Society angina score $\geq 3$, and grades of LV diastolic dysfunction $\geq 2$ were significantly negative predictors of good responders (all $p<0.01$ ). After administration of subcutaneous granulocyte-colony stimulating factor (G-CSF), a higher post-G-CSF neutrophil count in addition to the above four baseline variables also played crucial roles in early prediction of good response to CD34+ cell therapy for EnD-CAD (all $p<0.03$ ). The $\mathrm{H}$-L test displayed a good prediction power with sensitivity $83.3 \%$, specificity $85.3 \%$, and accuracy $84.4 \%$.

Conclusions: Using the results of our phase I/II clinical trials, previous smoking habit, female sex, lower grades of angina score, and diastolic dysfunction were identified to be independently predictive of "good response" to CD34+ cell therapy in the patients with EnD-CAD.

Trial registration: This is a retrospective analysis based on phase I (ISRCTN72853206) and II (ISRCTN26002902) clinical trials.

Keywords: CD34+ cell therapy, Good responders, Diffuse coronary artery disease, Refractory angina, Left ventricular ejection fraction

\section{Background}

Despite the state-of-the-art pharmacomodulation [1, 2], mature and skillful techniques in a coronary intervention such as percutaneous coronary intervention (PCI) $[3,4]$ and coronary artery bypass surgery (CABG) [5], continuous education [6], and renewal of guideline for the treatment of coronary artery disease (CAD) [7], the atherosclerotic cardiovascular disease, especially CAD, remains the leading cause of death worldwide. Accordingly, the treatment of CAD remains regrettably an unmet need currently. In light of the aforementioned observation, scientists and physicians are encouraged to seek some potentially therapeutic strategy for patients with complex or severe diffuse CAD who are not only non-candidates for surgical or percutaneous coronary intervention but also refractory to aggressive medical therapy. In fact, previous studies [8-10] in addition to our research [11, 12] have found that a significant number of patients with so-called end-stage diffuse CAD (EnD-CAD) suffered from a refractory symptom of dyspnea or angina and had rather high adverse clinical events and mortality.

Cell therapies for tissue and organ regeneration, including endothelial progenitor cells (EPCs) and mesenchymal stem cells (MSCs), have been extensively investigated in both animal studies and clinical trials in the past two decades [11-17]. Looking closer at these reports, a majority of these investigations done to date focused on the themes of EPC or MSC therapy in improving the ischemia-related heart dysfunction or associated symptoms [11-16]. Additionally, these reported studies [11-13, 18] have demonstrated cell therapies are attractive and promising with favorable clinical outcomes, including improvements in heart failure (HF) symptoms, angina, and left ventricular (LV) systolic function. Most this research $[11-13,18]$ found the improvement of LV ejection fraction (LVEF) $\geq 5.0$ to $7.0 \%$ was considered as a "great responder" after cell therapy for refractory angina or EnD-CAD. Surprisingly, while this consensus of "great response" to cell therapy is widely adopted, factors that can be used for the prediction of LVEF improvement $\geq 5.0$ to $7.0 \%$ have not yet been fully investigated. This could be attributed to the relatively small sample size in previous clinical trials adversely distorting the statistical significance. Currently, the quality assessment of efficacy and the evaluation of potency play key roles in determining the therapeutic success and acceptable quality of cell products [19, 20]. Early prediction of good or great response to cell-based therapy not only is cost-effective but also provides investigators or participants useful information regarding expected beneficial outcomes.

In fact, the patient number in our phase I and phase II clinical trials was actually relatively small so that a statistical significance of outcomes might be affected by the small sample size. Accordingly, this study was designed to identify which baseline or early factors have the potential to predict the great response in LVEF improvement after the circulatory-derived autologous CD34+ cell therapy for the treatment of EnD-CAD by aggregating the datasets of our phase I and II clinical trials.

\section{Material and methods Study population}

This is a retrospective study conducted in a tertiary medical center. Data were retrieved from our phase I clinical trial entitled "intra-coronary transfusion of circulation-derived CD34+ cells improves left ventricular function in patients with end-stage diffuse coronary artery disease unsuitable for coronary intervention" (registration number: ISRCTN72853206) [11] and phase II 
clinical trial entitled "intracoronary injection of autologous CD34+ cells improves 1-year left ventricular systolic function in patients with diffuse coronary artery disease and partially preserved cardiac performance unsuitable for coronary intervention-a randomized, openlabel, controlled phase II clinical trial (registration number: ISRCTN26002902) [21].

A total of 38 patients with EnD-CAD receiving intracoronary CD34+ cell therapy in phase I trial between December 2011 and March 2014, and 30 patients undergoing CD34+ cell therapy in phase II trial between December 2013 and November 2017, were selected in the present study. The inclusion and exclusion criteria have been thoroughly described in our clinical trials $[11,12,21]$. The written informed consent was obtained from all participants before enrollment. All variables in phase I/II trials were collected and subjected to detailed analysis.

The data acquisitions during the study period, including the clinical and laboratory parameters and imaging studies such as echocardiographic and coronary angiographic findings, have been approved by the Taiwan Food and Drug Administration (TFDA) (IRB No: 993985A [phase I], 1066062944 [phase II]) and the Institutional Review Committee on Human Research at Chang Gung Memorial Hospital (IRB No: 96-1381A [phase I], 201003985A0 [phase II]). Both phase I and II clinical trials were conducted at Kaohsiung Chang Gung Memorial Hospital, a tertiary referral center. Additionally, a longterm 5-year follow-up for phase I study was also permitted to perform in the same institute [12].

\section{Definition of "good responder" after cell therapy for EnD- CAD}

The good responder was defined as a 1-year improvement of LVEF $\geq 7.0 \%$ after CD34+ cell therapy for EnD-CAD. A cutoff value of $L V E F \geq 7.0 \%$ or $<7 \%$ was calculated by the average change of LVEF from baseline to 1-year measurement among all participants in our previous phase I $[11,12]$ and phase II trials [21]. This cutoff value was also considered reasonable after taking several previous reports $[13,22,23]$ as references in which the great responder was defined as the mean improvement of at least 5\% in LVEF after cell therapy.

\section{Definition of end-stage diffuse CAD (EnD-CAD)}

The definition of EnD-CAD has been described in detail in our previous phase I clinical trial [11]. Briefly, the EnD-CAD was confirmed by coronary angiographic findings which showed more than or equal to one obstructive CAD with severe diffuse morphological feature (defined as the diffuse lesion $\geq 50.0 \mathrm{~mm}$ in lengths, especially in relatively distal portion) or total occlusion of the vessel with an unclarified length of the obstruction and non-candidates for PCI or CABG (i.e., since vessel involvement was too diffuse and the diameter was too small for intervention).

\section{Retrospective collection of the variables and 1-year clinical follow-up}

Enrolled patients who successfully underwent stem cell therapy were followed-up for 1 year in the previous phase I/II studies [11, 21]. The baseline characteristics, laboratory data, bench-work results, and imaging findings of coronary angiography (CAG), transthoracic echocardiography, and cardiac magnetic resonance imaging were retrospectively retrieved from our stem cell research database that entered in computers during the previous phase I and II trials. The clinical and preclinical measures at baseline, after granulocyte colonystimulating factor (G-CSF) administration but prior to CD34+ cell therapy, as well as 1, 3, 6, 9, and 12 months after cell delivery were collected to ensure a thorough analysis. Each patient was regularly followed up at our outpatient clinic, and the relevant clinical information including presentation of symptoms, presence or absence of adverse clinical events, and drug prescription was recorded by research nurses with case report forms, as well as telephone interviews on an irregular basis.

\section{Procedure and protocol for CD34+ cell isolation}

The procedure and protocol were based on our previous report [11]. In detail, the number of CD34+ cells in the mononuclear cell preparation isolated during leukapheresis was enriched by utilizing a commercially available device [COBE Spectra 6.1 (Terumo BCT, INC.)] at 8:00 a.m. through a double lumen catheter inserted into the right femoral vein.

After a time-interval about four hours, an adequate amount of circulatory-derived CD34+ cells was collected and well prepared for intra-coronary infusion. According to the International Society of Hematotherapy and Grafting Engineering (ISHAGE) Guidelines for CD34+ cell determination with flow cytometric measurement of circulating CD34+ cells, hematological stem cells are characterized by the presence of surface markers CD34high/CD45dim/SSClow that were used to quantify the number of isolated CD34+ cells. The formula for the number of circulation-derived CD34+ cells was: number of CD34+ cells $=($ percentage of CD34+ cells $) \times \mathrm{WBC}$ count $\times 10^{3} \times$ peripheral-blood stem cell (PBSC) volume $(\mathrm{mL})$. The flow cytometric analysis followed the current guidelines of the College of American Pathology with a performance coefficient of variation $(\mathrm{CV})<4.0 \%$ (3.4 \pm $2.5)$ (by definition, $\mathrm{CV}<10.0 \%$ is acceptable).

After finishing the CD34+ collection without any cell culture for the differentiation of CD34, the patients were immediately sent to the cardiac catheterization room for receiving the intra-coronary $\mathrm{CD} 34+$ cell injection. 


\section{Laboratory assessment of circulating levels of soluble angiogenesis factors}

Circulating levels of vascular endothelial growth factor (VEGF), angiopoietin, epithelial growth factor (EGF), hepatocyte growth factor (HGF), transforming growth factor (TGF)- $\beta$, and stromal cell-derived growth factor (SDF)- $1 \alpha$, six indicators of soluble angiogenesis biomarkers were measured by duplicated determination with a commercially available ELISA method (R\&D Systems, Minneapolis, MN, USA). Intra-observer variability of the measurements was also assessed, and the mean intra-assay coefficients of variance were all $<4.5 \%$.

\section{Imaging studies}

Cardiac magnetic resonance image (MRI) was performed (i.e., prior to and at 6 months after cell therapy) by a radiologist blinded to the treatment allocation of the patients using the current standard evaluation method. In addition, 2D and 3D transthoracic echocardiography were performed by an experienced cardiologist blinded to the patient grouping. The procedure and protocol of $3 \mathrm{D}$ transthoracic echocardiography were previously described [12].

\section{Circulatory-derived mononuclear cells for EPC culture and Matrigel assay for evaluating angiogenesis}

The protocol and procedure of EPC culture and the assessment of angiogenesis were based on our previous report [24]. In brief, mononuclear cells (MNCs) were isolated cells and cultivated in differential endothelial cell culture medium (endothelial cell basal medium-2, Cambrex) with $10 \%$ fetal bovine serum (FBS), $50 \mathrm{U} / \mathrm{mL}$ penicillin, $50 \mathrm{~g} / \mathrm{mL}$ streptomycin, and $2 \mathrm{mmol} / \mathrm{L} \mathrm{L}$-glutamine (Invitrogen) with vascular endothelial growth factor (VEGF) and basic fibroblast growth factor (10 ng/ $\mathrm{mL}$ ) plated on gelatin-coated tissue culture flasks and incubated at $37^{\circ} \mathrm{C}$ with $5 \% \mathrm{CO}_{2}$ for 21 days. The culture medium was changed every $48 \mathrm{~h}$. By day 21, cells with spindle-shaped and cobblestone-like phenotype typical of endothelial cells were found attached on the plate.

The cells with endothelial cell phenotype were then plated in 96-well plates at $1.0 \times 104$ cells/well in $150 \mu \mathrm{L}$ serum-free M199 culture medium mixed with $50 \mu \mathrm{L}$ cold Matrigel (Chemicon International, Inc. Temecula, CA, USA) for $24 \mathrm{~h}$ using passages 3 to 4 EPCs incubated at $37{ }^{\circ} \mathrm{C}$ in $5 \% \mathrm{CO}_{2}$. Three random microscopic images $(200 \times)$ were taken from each well to count cluster, tube, and network formations and the mean values were derived. Both cumulative and mean tube lengths were calculated by Image-Pro Plus software (Media Cybernetics, Bethesda, MD, USA).

\section{Cardiopulmonary exercise testing}

Cardiopulmonary exercise testing (CPET) was used to objectively assess the patients' functional capacity. The result of peak oxygen update (peak $\mathrm{VO}_{2}$ ) at maximal exercise was recorded as metabolic equivalents, i.e., the best index of aerobic capacity and cardiorespiratory function.

\section{Statistical analysis}

All variables are expressed as mean \pm standard deviation or number with a percentage. Independent $t$ and MannWhitney $U$ tests were used to compare the difference in continuous variables between two groups as appropriate. For categorical variables between groups, the variables were compared with chi-square analysis with Fisher's exact test. Logistic regression models with univariate and multivariate analyses were performed to identify potential independent predictors of a good responder to cell therapy, followed by Hosmer-Lemeshow (H-L) test for goodness of fit in the logistic regression model. In addition, those variables with $p$ value $<0.08$ in univariate analysis were chosen into multivariate analysis for adjustment. Finally, a nomogram was drawn based on the identified predictors to facilitate the calculation of the probability rate of good response to cell therapy. Statistical analysis was performed using SPSS statistical software for Windows version 22 (SPSS for Windows, version 22; SPSS, IL, USA). A $p$ value $<0.05$ was considered statistically significant.

\section{Results}

\section{Baseline characteristics among the EnD-CAD patients}

(Table 1)

Among 68 subjects receiving CD34+ cell therapy, three patients in the phase II trial were excluded, including one case died of brain stem hemorrhage at 1 month, another one was expired of traumatic cervical spine injury with hypoxia at 1 month, and the other case refused to continue follow-up 1 week after cell delivery. A total of 65 study patients followed up for at least 6 months were selected for the analyses. All EnD-CAD patients expressed high-risk baseline profiles such as $100 \%$ for one of the atherosclerotic risk factors, $>76 \%$ for diabetes mellitus, $>90 \%$ for hypertension, $>87 \%$ for dyslipidemia, $70 \%$ for PCI history, 100\% for multi-vessel CAD, and > $50 \%$ for chronic total occlusion (CTO) at left anterior descending (LAD) artery. The age, gender, and rates of body mass index, old stroke, old myocardial infarction (MI), and CABG did not differ between 30 responders and 35 non-responders.

The laboratory finding showed that the white blood cell count was significantly lower in responders than in nonresponders. However, the platelet count, hemoglobin, estimated glomerulus filtration rate (eGFR), and serum 
Table 1 Baseline characteristics and variables at enrollment

\begin{tabular}{|c|c|c|c|c|}
\hline Variable & All $(N=65)$ & Responder $(N=30)$ & Non-responder $(N=35)$ & $P$ value \\
\hline \multicolumn{5}{|l|}{ Clinical feature } \\
\hline Age, year & $64.51 \pm 8.33$ & $65.47 \pm 8.86$ & $63.69 \pm 7.89$ & 0.395 \\
\hline Male sex, $n(\%)$ & $52(80.0 \%)$ & $21(70.0 \%)$ & $31(88.6 \%)$ & 0.062 \\
\hline Body height (cm) & $161.95 \pm 9.97$ & $162.4 \pm 7.8$ & $161.7 \pm 11.6$ & 0.781 \\
\hline Body weight (kg) & $69.68 \pm 10.93$ & $70.02 \pm 11.96$ & $69.38 \pm 10.13$ & 0.814 \\
\hline Body mass index $\left(\mathrm{kg} / \mathrm{m}^{2}\right)$ & $26.65 \pm 4.36$ & $26.50 \pm 3.71$ & $26.77 \pm 4.89$ & 0.990 \\
\hline Former smoker, $n(\%)$ & $26(40.0 \%)$ & $16(53.3 \%)$ & $10(28.6 \%)$ & 0.042 \\
\hline Hypertension, n (\%) & $59(90.8 \%)$ & $26(86.7 \%)$ & $33(94.3 \%)$ & 0.403 \\
\hline Diabetes mellitus, $n(\%)$ & $50(76.9 \%)$ & $23(76.7 \%)$ & $27(77.1 \%)$ & 0.964 \\
\hline Dyslipidemia, $n$ (\%) & $57(87.7 \%)$ & $25(83.3 \%)$ & $32(91.4 \%)$ & 0.455 \\
\hline Old stroke, $n(\%)$ & $26(23.1 \%)$ & $8(26.7 \%)$ & $7(20.0 \%)$ & 0.525 \\
\hline Old myocardial infarction, $n$ (\%) & $16(24.6 \%)$ & $5(16.7 \%)$ & $11(31.4 \%)$ & 0.168 \\
\hline Chronic hepatitis B or C, $n$ (\%) & $5(7.7 \%)$ & $1(3.3 \%)$ & $4(11.4 \%)$ & 0.363 \\
\hline History of CABG, $n(\%)$ & $22(33.8 \%)$ & $7(23.3 \%)$ & 15 (49.2\%) & 0.097 \\
\hline History of $\mathrm{PCl}, n(\%)$ & $45(69.2 \%)$ & $21(70.0 \%)$ & $24(68.6 \%)$ & 0.901 \\
\hline Left main involvement, $n(\%)$ & 19 (29.2\%) & $7(23.3 \%)$ & $12(34.3 \%)$ & 0.333 \\
\hline Multi-vessel CAD, $n(\%)$ & $68(100 \%)$ & $40(100 \%)$ & $28(100 \%)$ & 1.000 \\
\hline CTO at LAD, $n(\%)$ & 35 (53.8\%) & $16(53.3 \%)$ & 19 (54.3\%) & 0.939 \\
\hline \multicolumn{5}{|l|}{ Laboratory data } \\
\hline 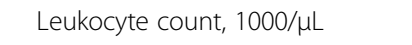 & $7.00 \pm 2.00$ & $6.50 \pm 2.07$ & $7.44 \pm 1.86$ & 0.017 \\
\hline Hemoglobin, g/dL & $13.24 \pm 1.87$ & $13.14 \pm 2.04$ & $13.32 \pm 1.73$ & 0.707 \\
\hline 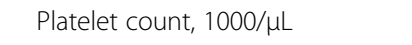 & $201.88 \pm 57.11$ & $193.1 \pm 44.3$ & $209.4 \pm 65.9$ & 0.254 \\
\hline Serum creatinine, mg/dL & $1.28 \pm 0.52$ & $1.25 \pm 0.56$ & $1.31 \pm 0.48$ & 0.116 \\
\hline eGFR, $\mathrm{ml} / \mathrm{min} / 1.73 \mathrm{~m}^{2}$ & $61.33 \pm 21.53$ & $62.19 \pm 22.73$ & $60.60 \pm 20.74$ & 0.770 \\
\hline Serum sodium, mEq/L & $140.11 \pm 2.69$ & $140.30 \pm 2.89$ & $139.94 \pm 2.54$ & 0.531 \\
\hline Serum potassium, mEq/L & $4.28 \pm 0.42$ & $4.35 \pm 0.40$ & $4.22 \pm 0.44$ & 0.231 \\
\hline Alanine aminotransferase, $U / L$ & $27.02 \pm 23.33$ & $27.67 \pm 28.88$ & $26.46 \pm 17.68$ & 0.594 \\
\hline Total cholesterol, mg/dL & $163.49 \pm 42.01$ & $167.03 \pm 36.86$ & $160.46 \pm 26.30$ & 0.378 \\
\hline Low-density lipoprotein, mg/dL & $96.23 \pm 36.34$ & $99.03 \pm 34.73$ & $93.83 \pm 38.00$ & 0.569 \\
\hline High-density lipoprotein, mg/dL & $43.74 \pm 9.79$ & $43.97 \pm 11.29$ & $43.54 \pm 8.45$ & 0.863 \\
\hline Triglyceride, mg/dL & $143.20 \pm 79.20$ & $132.13 \pm 49.16$ & $152.69 \pm 97.71$ & 0.989 \\
\hline \multicolumn{5}{|l|}{ Medication } \\
\hline Antiplatelet, $n(\%)$ & $65(100.0 \%)$ & $30(100.0 \%)$ & $35(100.0 \%)$ & 1.000 \\
\hline Anticoagulant, $n(\%)$ & $2(3.1 \%)$ & $0(0.0 \%)$ & $2(5.7 \%)$ & 0.495 \\
\hline Beta-blocker, $n(\%)$ & $58(89.2 \%)$ & $20(100.0 \%)$ & $28(80.0 \%)$ & 0.013 \\
\hline RAS inhibitor, $n(\%)$ & $54(83.1 \%)$ & $23(76.7 \%)$ & $31(88.6 \%)$ & 0.202 \\
\hline Calcium channel blocker, $n$ (\%) & $31(47.7 \%)$ & $12(40.0 \%)$ & 19 (54.3\%) & 0.250 \\
\hline Diuretic, $n(\%)$ & $22(33.8 \%)$ & $6(20.0 \%)$ & $16(45.7 \%)$ & 0.029 \\
\hline Lipid lowering agent, $n(\%)$ & $45(69.2 \%)$ & $20(66.7 \%)$ & $25(71.4 \%)$ & 0.678 \\
\hline Vasodilator, $n(\%)$ & $2(3.1 \%)$ & $0(0.0 \%)$ & $2(5.7 \%)$ & 0.495 \\
\hline
\end{tabular}

Notes: Responder was defined as 1-year improvement of LVEF $\geq 7.0 \%$ after cell-based therapy for EnD-CAD. Data are expressed as mean \pm standard deviation or number (percentage). Abbreviation: $C A B G$ coronary artery bypass grafting surgery, $P C l$ percutaneous coronary intervention, $C A D$ coronary artery disease, $C T O$ chronic total occlusion, $L A D$ left anterior descending artery, eGFR estimated glomerular filtration rate, RAS renin-angiotensin system 
creatinine, total cholesterol, high-density lipoprotein, lowdensity lipoprotein, and triglyceride did not differ between the two groups.

In addition, responders had a significantly higher prescription of beta-blocker and lower diuretic use than the non-responders. All patients took antithrombotic agents and a majority of them received guideline-directed medical therapy.

\section{Laboratory parameters after G-CSF injection, clinical presentations, and results of examinations during follow- up, and 1-year outcomes (Table 2)}

The post-G-CSF laboratory findings demonstrated that the circulating levels of leukocyte count, hematopoietic stem cells, young cells, neutrophils, CD34+ cells, CD45+ cells, and stem cell percentage measured by flow cytometric analysis, as well as troponin-I did not differ between the two groups.

The responders had significantly lower angina severity and insignificantly less dyspnea compared with the nonresponders prior to $\mathrm{CD} 34+$ cell therapy. Within the follow-up period, the responders had better clinical symptomatic improvement in both angina and HF as compared with the non-responders at the time points of every 3 months, indicating the improvement of cardiac systolic function (i.e., LVEF improvement $\geq 7.0 \%$ ) was correlated with the relief of clinical symptoms.

Regarding objective evaluations for functional capacity, angiogenesis, chamber sizes, and cardiac/valvular functions, there were no significant differences between groups at baseline. However, the responders had higher coronary angiogenesis score and less echocardiographic grade 2 or 3 diastolic dysfunction than the nonresponders. Notably, the difference of LVEF on 3D echocardiography between the follow-up period and baseline began to be significant at 3 months after stem cell therapy, implicating good clinical, and subclinical responses could be observed as early as 3 months since delivery of CD34+ cells. After 1-year follow-up, composite endpoints occurred in nearly one half of EnD-CAD patients but did not differ between the two groups. Around 1 in 5 patients needed hospitalization for acute decompensated HF, and nearly 1 in 4 patients received salvage myocardial revascularization strategy for relief of refractory angina in both groups.

Identification of "predictors of good responder" to CD34+ cell therapy from baseline characteristics or presentations (Table 3, Figs. 1 and 2)

To understand which baseline variable could be predictive of a good responder prior to CD34+ cell therapy in patients with EnD-CAD, logistic regression analysis was performed. In univariate analysis, male gender, higher baseline leukocyte count, CCS angina score $\geq 3$, and grade of diastolic dysfunction $\geq 2$ were identified as potentially poor responders to the cell therapy. On the contrary, a former smoker and higher baseline angiogenesis score could be used to predict good response to the cell therapy. After multivariate adjustment for the above potential variables, the "presence" of the former smoker and "absence" of the male gender, Canadian Cardiovascular Society (CCS) angina score $\geq 3$, and grade of diastolic dysfunction $\geq 2$ on the initial survey were identified as independent predictors of good responder after stem cell therapy.

H-L test shown in Fig. 1a demonstrated sensitivity $86.7 \%$, specificity $70.6 \%$, and accuracy $78.1 \%$ after considering the above four predictors $(P=0.777$, which was higher than the cutoff value of 0.5 ). To facilitate an efficient evaluation in clinical practice, the nomogram in Fig. 2 was utilized to calculate the estimated good response rate of CD34+ cell therapy for EnD-CAD. Summation of individual points available from gender, former smoker, CCS angina score, and grade of diastolic dysfunction helps researchers to assess the probability of good responder when EnD-CAD patients are enrolled as candidates for cell therapy.

\section{Identification of "early predictors of good responder" after receiving G-CSF injection or CD34+ cell therapy} (Table 4, Fig. 1 and Supplemental Table 1)

Owing to a lot of useful information available after administering G-CSF or transfusing CD34+ cells, those variables viable to be recognized as "early predictors" of a good responder, e.g., the vasculogenic activity of stem cells, biomarkers before and after G-CSF injection, and detailed imaging for angiogenesis (refer to Supplemental Table 1), were collected and added to the logistic regression analysis. Table 4 shows in addition to the four aforementioned baseline characteristics, the elevation of post G-CSF-treated neutrophil count was found negatively associated with good response to the cell therapy after multivariate adjustment. After adding this newlyidentified independent predictor to the H-L test, a better predictor power was obtained with sensitivity $83.3 \%$, specificity $85.3 \%$, and accuracy $84.4 \%(p=0.881$, which was much higher than the cutoff value of 0.5) (Fig. 1b). Regrettably, we did not further identify other potential predictors of good responder from remaining variables after G-CSF, prior to, or after stem cell therapy.

As shown in Supplemental Table 1, the responders had significantly higher soluble angiogenesis levels of vascular endothelial growth factor (VEGF) and hepatocytes growth factor (HGF) in circulation as compared with the nonresponders. On the other hand, the circulatory level of stromal cell-derived factor (SDF)- $1 \alpha$, another angiogenic/ proinflammatory factor, was consistently lower in the responders than in the non-responders prior to and after G- 
Table 2 Variables within follow-up period and clinical outcomes

\begin{tabular}{|c|c|c|c|c|}
\hline Variable & All $(N=65)$ & Responder $(N=30)$ & Non-responder $(N=35)$ & $P$ value \\
\hline \multicolumn{5}{|l|}{ Post-GCSF biomarkers } \\
\hline 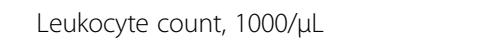 & $42.29 \pm 10.76$ & $39.49 \pm 10.34$ & $44.69 \pm 10.67$ & 0.051 \\
\hline Hematopoietic progenitor cell, $\mu \mathrm{L}$ & $49.78 \pm 46.68$ & $37.00 \pm 29.01$ & $59.56 \pm 55.05$ & 0.105 \\
\hline Young cell, \% & $7.21 \pm 5.06$ & $7.10 \pm 4.93$ & $7.30 \pm 5.23$ & 0.859 \\
\hline Segment, $\%$ & $77.14 \pm 7.86$ & $76.86 \pm 7.60$ & $77.39 \pm 8.18$ & 0.790 \\
\hline Neutrophil count, $1000 / \mu \mathrm{L}$ & $32.76 \pm 9.31$ & $30.66 \pm 9.44$ & $34.56 \pm 8.94$ & 0.093 \\
\hline Flow data: stem cell, \% & $0.35 \pm 0.24$ & $0.30 \pm 0.18$ & $0.40 \pm 0.28$ & 0.226 \\
\hline Performance CV, \% & $4.68 \pm 2.67$ & $4.46 \pm 2.71$ & $4.87 \pm 2.65$ & 0.540 \\
\hline CD34+ cell, 1000/uL & $1.27 \pm 0.90$ & $0.87 \pm 0.50$ & $1.49 \pm 1.00$ & 0.076 \\
\hline CD45+ cell, 1000/uL & $343.05 \pm 100.35$ & $297.66 \pm 103.38$ & $366.74 \pm 92.24$ & 0.082 \\
\hline Troponin-I after cell therapy & $1.24 \pm 3.30$ & $1.02 \pm 2.64$ & $1.42 \pm 3.78$ & 0.430 \\
\hline \multicolumn{5}{|l|}{ Clinical presentation } \\
\hline CCS angina score at baseline & $2.55 \pm 0.75$ & $2.27 \pm 0.64$ & $2.80 \pm 0.58$ & 0.003 \\
\hline CCS angina score $\geq 3, n(\%)$ & $36(55.4 \%)$ & $11(36.7 \%)$ & $25(71.4 \%)$ & 0.005 \\
\hline CCS angina score at 3 months & $0.57 \pm 0.77$ & $0.33 \pm 0.55$ & $0.77 \pm 0.88$ & 0.021 \\
\hline CCS angina score at 6 months & $0.50 \pm 0.74$ & $0.38 \pm 0.62$ & $0.60 \pm 0.66$ & 0.282 \\
\hline CCS angina score at 12 months & $0.33 \pm 0.57$ & $0.17 \pm 0.47$ & $0.47 \pm 0.62$ & 0.021 \\
\hline NYHA Fc of dyspnea at baseline & $1.71 \pm 1.13$ & $1.43 \pm 1.17$ & $1.94 \pm 1.06$ & 0.086 \\
\hline NYHA Fc of dyspnea at 3 months & $0.71 \pm 0.88$ & $0.37 \pm 0.62$ & $1.00 \pm 0.97$ & 0.003 \\
\hline NYHA Fc of dyspnea at 6 months & $0.53 \pm 0.87$ & $0.17 \pm 0.47$ & $0.83 \pm 1.01$ & 0.001 \\
\hline NYHA Fc of dyspnea at 12 months & $0.54 \pm 0.90$ & $0.21 \pm 0.56$ & $0.82 \pm 1.03$ & 0.002 \\
\hline \multicolumn{5}{|l|}{ Examination } \\
\hline Endothelial dysfunction* ${ }^{*} n(\%)$ & $38(64.4 \%)$ & $15(57.7 \%)$ & $23(69.7 \%)$ & 0.339 \\
\hline CPET METs at baseline & $5.08 \pm 1.17$ & $4.83 \pm 1.19$ & $5.24 \pm 1.16$ & 0.255 \\
\hline CPET METs at 6 months & $5.33 \pm 1.44$ & $5.22 \pm 1.44$ & $5.38 \pm 1.46$ & 0.750 \\
\hline Difference of METs 6 months vs. baseline & $0.17 \pm 1.20$ & $0.47 \pm 0.86$ & $0.01 \pm 1.33$ & 0.252 \\
\hline CMR LVEF at baseline, \% & $50.31 \pm 14.52$ & $52.69 \pm 13.28$ & $48.21 \pm 15.42$ & 0.214 \\
\hline CMR LVEF at 6 months, \% & $52.93 \pm 14.08$ & $56.25 \pm 12.33$ & $50.03 \pm 15.05$ & 0.098 \\
\hline Difference of LVEF ${ }^{6}$ months vs. baseline & $2.02 \pm 4.96$ & $2.71 \pm 3.87$ & $1.41 \pm 5.74$ & 0.312 \\
\hline Angiogenesis score at baseline & $1.57 \pm 0.63$ & $1.73 \pm 0.57$ & $1.43 \pm 0.66$ & 0.048 \\
\hline Angiogenesis score $\geq 2, n(\%)$ & $36(56.3 \%)$ & $20(66.7 \%)$ & $16(47.1 \%)$ & 0.115 \\
\hline Angiogenesis score at 9 months & $2.60 \pm 0.83$ & $2.65 \pm 0.70$ & $2.56 \pm 0.94$ & 0.955 \\
\hline 3D echo LVEF at baseline, \% & $51.30 \pm 10.62$ & $49.41 \pm 10.38$ & $52.91 \pm 10.71$ & 0.188 \\
\hline 3D echo LVEF $\geq 50 \%, n(\%)$ & $40(61.5 \%)$ & $17(56.7 \%)$ & $23(65.7 \%)$ & 0.455 \\
\hline 3D echo LVEF $\leq 40 \%, n(\%)$ & $9(13.8 \%)$ & $6(20.0 \%)$ & $3(8.6 \%)$ & 0.282 \\
\hline 3D echo LVEF at 3 months, $\%$ & $55.01 \pm 11.46$ & $56.18 \pm 11.36$ & $54.11 \pm 11.63$ & 0.494 \\
\hline Difference of 3D LVEF 3 months vs. baseline & $3.24 \pm 5.91$ & $5.71 \pm 5.60$ & $1.35 \pm 5.49$ & 0.002 \\
\hline 3D echo LVEF at 6 months, $\%$ & $56.45 \pm 12.56$ & $57.40 \pm 13.74$ & $55.67 \pm 11.64$ & 0.359 \\
\hline Difference of 3D LVEF 6 months vs. baseline & $4.89 \pm 7.94$ & $7.47 \pm 10.06$ & $2.76 \pm 4.80$ & $<0.001$ \\
\hline \multicolumn{5}{|l|}{ Baseline echocardiography } \\
\hline LA diameter, $\mathrm{mm}$ & $42.17 \pm 5.39$ & $42.70 \pm 4.94$ & $41.71 \pm 5.79$ & 0.369 \\
\hline LVEDD, mm & $53.25 \pm 8.42$ & $53.22 \pm 8.37$ & $53.27 \pm 8.59$ & 0.981 \\
\hline 2D echo LVEF, \% & $54.32 \pm 13.03$ & $53.85 \pm 13.82$ & $54.72 \pm 12.51$ & 0.790 \\
\hline Grade 2 or 3 diast. dysfxn, $n(\%)$ & $26(40.6 \%)$ & $7(23.3 \%)$ & 19 (55.9\%) & 0.008 \\
\hline
\end{tabular}


Table 2 Variables within follow-up period and clinical outcomes (Continued)

\begin{tabular}{|c|c|c|c|c|}
\hline Variable & All $(N=65)$ & Responder $(N=30)$ & Non-responder $(N=35)$ & $P$ value \\
\hline TVPG, mmHg & $18.32 \pm 11.66$ & $19.52 \pm 13.16$ & $17.31 \pm 10.33$ & 0.568 \\
\hline Moderate to severe MR, $n(\%)$ & $9(13.8 \%)$ & $5(16.7 \%)$ & $4(11.4 \%)$ & 0.722 \\
\hline 3D echo LVEDV, $\mathrm{mm}^{3}$ & $87.11 \pm 27.14$ & $86.60 \pm 26.43$ & $87.51 \pm 28.08$ & 0.896 \\
\hline Systolic dyssynchrony index, \% & $7.75 \pm 7.25$ & $8.48 \pm 8.81$ & $7.10 \pm 5.54$ & 0.850 \\
\hline \multicolumn{5}{|l|}{ Outcome at 1 year } \\
\hline Composite endpoints ${ }^{\dagger}, n(\%)$ & $31(47.7 \%)$ & $14(46.7 \%)$ & $17(48.6 \%)$ & 0.878 \\
\hline All-cause mortality, $n$ (\%) & $10(15.4 \%)$ & $4(13.3 \%)$ & $6(17.1 \%)$ & 0.742 \\
\hline Cardiovascular death, $n$ (\%) & $1(1.5 \%)$ & $1(3.3 \%)$ & $0(0.0 \%)$ & 0.462 \\
\hline Acute myocardial infarction, $n(\%)$ & $3(4.6 \%)$ & $1(3.3 \%)$ & $2(5.7 \%)$ & 1.000 \\
\hline Hospitalization for HF, n (\%) & $13(20.0 \%)$ & $6(20.0 \%)$ & $7(20.0 \%)$ & 1.000 \\
\hline Revascularization, $n(\%)$ & $16(24.6 \%)$ & $9(30.0 \%)$ & $7(20.0 \%)$ & 0.351 \\
\hline Sepsis, n (\%) & 6 (12.3\%) & $2(6.7 \%)$ & 6 (17.1\%) & 0.270 \\
\hline
\end{tabular}

Notes: Responder was defined as 1-year improvement of LVEF $\geq 7.0 \%$ after cell-based therapy for EnD-CAD. Data are expressed as mean \pm standard deviation or number (percentage)

Abbreviation: GCSF granulocyte-colony stimulating factor, CV coefficient of variability, CCS Canadian Cardiovascular Society, NYHA FC New York Heart Association functional classification, CPET cardiopulmonary exercise testing, MET metabolic equivalent of task, CMR cardiovascular magnetic resonance imaging, LVEF left ventricular ejection fraction, $3 D$ echo three-dimensional echocardiography, $2 D$ echo two-dimensional echocardiography, $L A$ left atrium, $L V E D D$ left ventricular enddiastolic diameter, diast. dysfxn diastolic dysfunction, TVPG trans-tricuspid valve pressure gradient, MR mitral regurgitation, LVEDV left ventricular end-diastolic volume, $H F$ heart failure

*Endothelial dysfunction was defined as post-nitroglycerin flow-mediated dilatation of brachial artery $<300 \%$

${ }^{\dagger}$ Composite endpoints were comprised of all-cause mortality, major adverse cardiac or cerebrovascular events (defined as cardiovascular death, acute myocardial infarction, or stroke), hospitalization for heart failure, or unexpected revascularization

CSF injections as well as after CD34+ cell therapy. Additionally, SDF- $1 \alpha$ levels in coronary sinus checked at different time points were also significantly lower in the former group than in the latter one. However, coronary angiogenesis on Wimasis analysis, angiogenic capacity on Matrigel assay, and levels of angiopoietin (ANP)-1, epidermal growth factor (EGF), and transforming growth factor (TGF)$\beta 1$ (i.e., three soluble angiogenesis factors) on enzyme-linked immunosorbent assay (ELISA) did not differ between the two groups, suggesting prediction of a good responder to cell therapy was mainly dependent on baseline characteristics rather than on those variables collected after G-CSF or CD34+ cell therapy. These findings were very useful and practical on the screening for potential good responders to the cell therapy in the early stage of the trial.

\section{Discussion}

This study which utilized and analyzed the parameters from our phase I/II clinical trials delineated several fundamental clinical-relevant information. First, the baseline variables of female gender and former smoker were significantly and positively predictive of, whereas the advanced angina score (i.e., CCS angina score $\geq 3$ ) and moderate to severe LV diastolic dysfunction (i.e., grade $\geq$ 2) were negatively predictive of, good response to CD34+ cell therapy for EnD-CAD. Second, increased neutrophil count after G-CSF treatment not only was negatively predictive of good response to the cell therapy but also augmented the predictive power when it was considered in addition to the four aforementioned baseline variables. Third, most predictors of a good responder were identified based on patient's baseline characteristics and laboratory/examination findings, suggesting that we are able to expect the probability of effectiveness and responsiveness before conducting expensive cell-based therapy.

It is well recognized that regenerative medicine is currently of paramount importance for organ dysfunction, especially for those patients with ischemia-related LV dysfunction. Abundant data [11-16, 18-20] have also supported that cell therapy is an alternative to conventional anti-ischemic treatment for the patients with intractable ischemic cardiomyopathy, complex diffuse coronary stenotic lesions, and refractory angina. However, not all the patients with EnD-CAD who received cell therapy had satisfactory clinical outcomes and prominent improvement of LV function. This issue drives the investigators $[13,22,23]$ trying to integrate the consensus of improvement of LVEF $\geq 5.0$ to $7.0 \%$ to be recognized as the "acceptable or great response" after cell therapy. Surprisingly, how many (i.e., percentage) or what kind of EnD-CAD patients met the criteria of "great response" to cell therapy have not yet been identified. One novel finding in the present study was that the analytical results of pooled data from our phases I/II trials showed that nearly $50 \%$ of CD34+ cell treated patients met the criteria of "good responders", i.e., LVEF improved $\geq 7.0 \%$. Our finding, in addition to extending 
Table 3 Baseline predictors of "good responder" before IC CD34+ therapy for EnD-CAD

\begin{tabular}{|c|c|c|c|c|c|c|}
\hline \multirow{2}{*}{$\begin{array}{l}\text { LVEF improvement } \geq 7.0 \% \\
\text { Variables }\end{array}$} & \multicolumn{3}{|c|}{ Univariate analysis } & \multicolumn{3}{|c|}{ Multivariate analysis } \\
\hline & OR & $95 \% \mathrm{Cl}$ & $P$ value & $\overline{\mathrm{OR}}$ & $95 \% \mathrm{Cl}$ & $P$ value \\
\hline \multicolumn{7}{|l|}{ Baseline characteristics } \\
\hline Age per year & 1.027 & $0.967-1.090$ & 0.389 & & & \\
\hline Age $\geq 65$ years & 1.524 & $0.571-4.065$ & 0.400 & & & \\
\hline Male sex & 0.301 & $0.082-1.106$ & 0.071 & 0.028 & $0.003-0.261$ & 0.002 \\
\hline Body mass index & 0.985 & $0.879-1.104$ & 0.799 & & & \\
\hline Former smoker & 2.857 & $1.024-7.970$ & 0.045 & 8.898 & $1.891-41.858$ & 0.006 \\
\hline Diabetes mellitus & 1.102 & $0.357-3.405$ & 0.866 & & & \\
\hline Atherosclerotic risk factor* & $n / a$ & $\mathrm{n} / \mathrm{a}$ & $n / a$ & & & \\
\hline Old stroke or old Ml & 0.706 & $0.263-1.893$ & 0.489 & & & \\
\hline Chronic hepatitis B or C & 0.267 & $0.028-2.533$ & 0.250 & & & \\
\hline History of CABG & 0.406 & $0.138-1.194$ & 0.101 & & & \\
\hline Left main involvement & 0.583 & $0.195-1.747$ & 0.335 & & & \\
\hline CTO at LAD & 0.962 & $0.362-2.560$ & 0.939 & & & \\
\hline Leukocyte count & 0.765 & $0.576-1.018$ & 0.066 & 0.860 & $0.632-1.170$ & 0.077 \\
\hline Hemoglobin & 0.950 & $0.729-1.237$ & 0.702 & & & \\
\hline Serum creatinine & 0.776 & $0.292-2.060$ & 0.610 & & & \\
\hline eGFR & 1.003 & $0.981-1.027$ & 0.766 & & & \\
\hline Total Cholesterol & 1.004 & $0.992-1.016$ & 0.528 & & & \\
\hline Beta blocker & $n / a$ & $\mathrm{n} / \mathrm{a}$ & $\mathrm{n} / \mathrm{a}$ & & & \\
\hline RAS inhibitor & 0.424 & $0.111-1.622$ & 0.210 & & & \\
\hline Lipid lowering agent & 0.800 & $0.278-2.299$ & 0.679 & & & \\
\hline \multicolumn{7}{|l|}{ Presentation and exams at baseline } \\
\hline CCS angina score $\geq 3$ & 0.232 & $0.082-0.658$ & 0.006 & 0.138 & $0.033-0.576$ & 0.007 \\
\hline NYHA FC of dyspnea $\geq 3$ & 0.664 & $0.220-2.009$ & 0.468 & & & \\
\hline Endothelial dysfunction & 0.593 & $0.202-1.738$ & 0.341 & & & \\
\hline CPET-METS & 0.732 & $0.429-1.246$ & 0.250 & & & \\
\hline CMR LVEF & 1.022 & $0.987-1.059$ & 0.225 & & & \\
\hline Angiogenesis score $\geq 2$ & 2.250 & $0.816-6.207$ & 0.117 & & & \\
\hline 3D echo LVEF & 0.968 & $0.923-1.106$ & 0.187 & & & \\
\hline $3 \mathrm{D}$ echo LVEF $\quad \geq 50 \%$ & 0.682 & $0.250-1.863$ & 0.456 & & & \\
\hline 3 D echo LVEF $\leq 40 \%$ & 2.667 & $0.605-11.756$ & 0.195 & & & \\
\hline \multicolumn{7}{|l|}{ Baseline echocardiography } \\
\hline LA diameter & 1.035 & $0.944-1.136$ & 0.461 & & & \\
\hline LVEDD & 0.999 & $0.943-1.059$ & 0.980 & & & \\
\hline 2D echo LVEF & 0.995 & $0.958-1.033$ & 0.786 & & & \\
\hline Grade 2 or 3 diast. dysfxn & 0.240 & $0.081-0.710$ & 0.010 & 0.104 & $0.022-0.505$ & 0.005 \\
\hline TVPG & 1.017 & $0.972-1.064$ & 0.469 & & & \\
\hline Moderate to severe MR & 1.550 & $0.376-6.390$ & 0.544 & & & \\
\hline 3D echo LVEDV & 0.999 & $0.980-1.017$ & 0.894 & & & \\
\hline Systolic dyssynchrony index & 1.028 & $0.955-1.106$ & 0.466 & & & \\
\hline
\end{tabular}

Notes: Abbreviation: IC intracoronary, EnD-CAD end-stage diffuse coronary artery disease, $L V E F$ left ventricular ejection fraction, $O R$ odds ratio, $C I$ confidence interval, $n / a$ not applicable, $M I$ myocardial infarction, CABG coronary artery bypass grafting surgery, CTO chronic total occlusion, $L A D$ left anterior descending artery, eGFR estimated glomerular filtration rate, RAS renin-angiotensin system, CCS Canadian Cardiovascular Society, NYHA FC New York Heart Association functional classification, CPET cardiopulmonary exercise testing, MET metabolic equivalent of task, CMR Cardiovascular magnetic resonance imaging, $L V E F$ left ventricular ejection fraction, $3 D$ echo three-dimensional echocardiography, $L A$ left atrium, $L V E D D$ left ventricular end-diastolic diameter, $2 D$ echo two-dimensional echocardiography, diast. dysfxn diastolic dysfunction, TVPG trans-tricuspid valve pressure gradient, MR mitral regurgitation, LVEDV left ventricular end-diastolic volume

${ }^{*}$ Atherosclerotic risk factors indicate hypertension, diabetes, or dyslipidemia; data was not available because all EnD-CAD patients had at least one of the atherosclerotic risk factors 


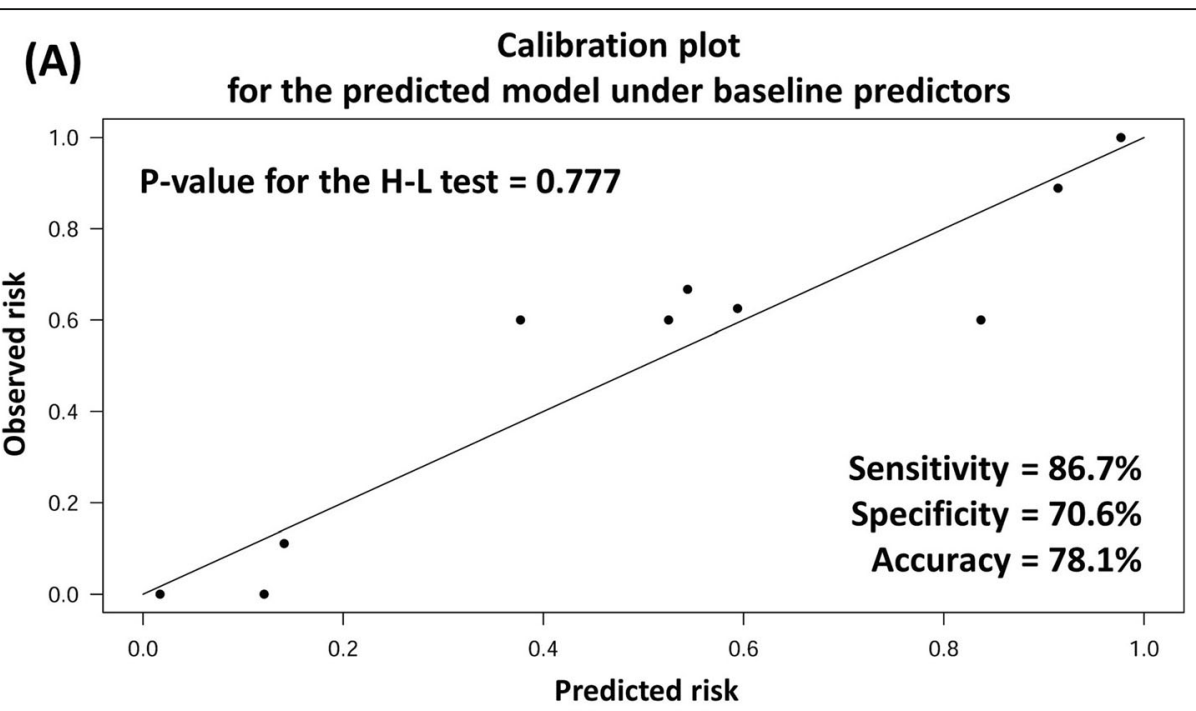

(B)

Calibration plot

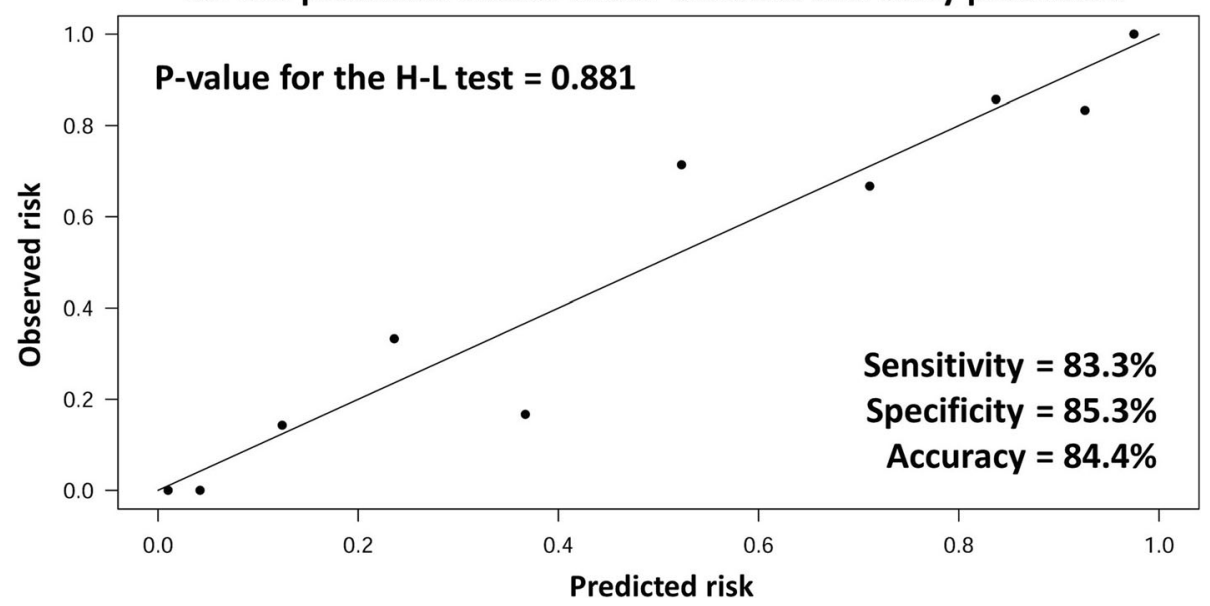

Fig. 1 Hosmer-Lemeshow (H-L) test for goodness of fit in the logistic regression model. a Sensitivity $86.7 \%$, specificity $70.6 \%$, and accuracy $78.1 \%$ were available after the adoption of logistic regression analysis with multivariate adjustment for the male sex, past smoker, baseline CCS angina score $\geq 3$, and grade $2 / 3$ diastolic dysfunction. $P$ value for the goodness of fit with $\mathrm{H}$-L test was 0.777 when cutoff point was set as 0.5 . $\mathbf{b}$ After adding the variable of post-G-CSF neutrophil count to the aforementioned four variables, sensitivity $83.3 \%$, specificity $85.3 \%$, and accuracy $84.4 \%$ were obtained for a better prediction. The $P$ value for $\mathrm{H}$-L test was 0.881 (cutoff point 0.5). Abbreviation: CCS = Canadian Cardiovascular Society; $\mathrm{G}-\mathrm{CSF}=$ granulocyte-colony stimulating factor

the findings of the previous studies, $[13,22,23]$ is the first one to highlight the early prediction of "good responders" and certainly would provide useful information in future clinical cell-based researches for the treatment of refractory angina or EnD-CAD.

Despite the important issue of good response after cell therapy has been extensively investigated and 5.0 to $7.0 \%$ of improvement in LVEF is viewed as a well acceptable value [13, 22, 23], so far, no study has reported which variables could be served as independent predictors of good response to cell-based therapy in the field of ischemic heart disease. In fact, there is only one similar study [25] which identified age, blood fibrinogen, arterial occlusion level, transcutaneous pressure of oxygen, and the transplanted CD34+ cell count were significant prognostic factors of the responders in patients with nooption critical limb ischemia. Somewhat different from the analytic results in the former study [25], our findings in the present study emphasized the importance of baseline patients' characteristics rather than laboratory variables or lesion complexities. As for the patients with EnD-CAD, we successfully identified that the baseline variables of female gender and former smoker were independently predictive of good responders of CD34+ cell therapy, whereas the advanced angina score and diastolic dysfunction were two independent predictors of non- 


\section{Nomogram for predicting good responder to stem cell therapy}

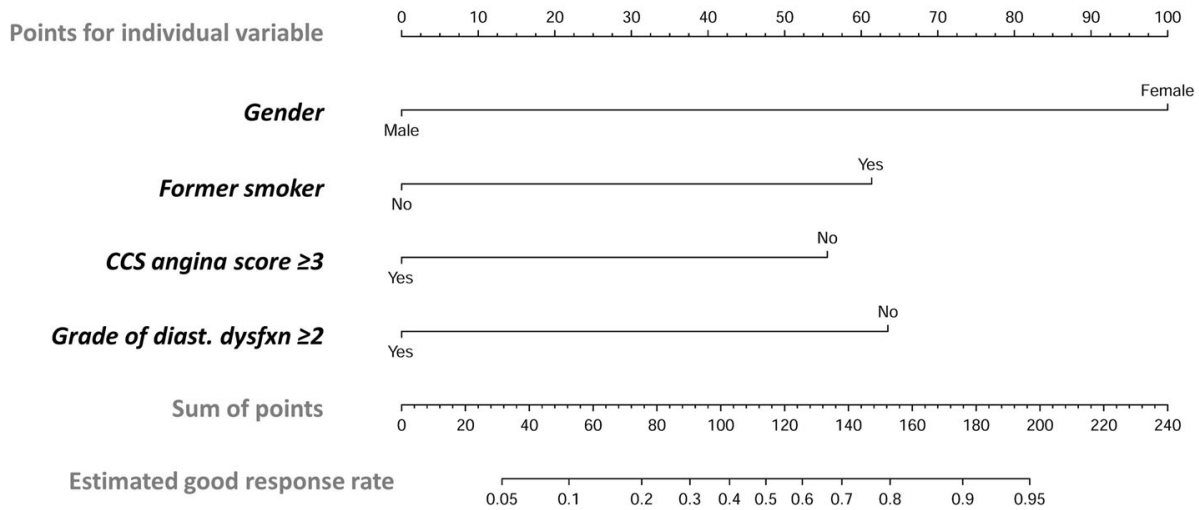

Fig. 2 Nomogram for scaling a good response rate to stem cell therapy for EnD-CAD. The nomogram was designed for scaling and calculating the probability of good response rate to cell therapy for patients with EnD-CAD by using individual baseline variable. The scales could help investigators to calculate the response rate and further predict who will be a "good responder" before applying cell infusion to treat EnD-CAD or refractory angina. Abbreviation: EnD-CAD = end-stage diffuse coronary artery disease; CCS = Canadian Cardiovascular Society; diast.

Dysfxn = diastolic dysfunction

responders of CD34+ cell therapy. Of distinctive finding was that an increase in the neutrophil count after G-CSF treatment was another negative predictor of nonresponder to cell therapy. Our findings, therefore, provide extremely useful research information on the screening and enrollment of suitable candidates for receiving CD34+ cell therapy, especially for those EnDCAD patients who are refractory to conventional therapy.

We found discrepancies among improvements of LVEF, presentation of HF symptoms, and unfavorable clinical outcomes. In many clinical circumstances, LVEF is not consistent with the New York Heart Association functional class because the latter is namely dependent on patient's physiological adaptation, metabolic status, oxygen consumption, and myocardial oxygen balance determined by the ratio of oxygen supply to oxygen demand [26]. Therefore, besides N-terminal pro-brain natriuretic peptide level, LVEF, 6-min walk distances, and CPET, well-designed questionnaires are suggested for functional evaluation and risk stratification in HF patients [27].

There is a close association between an increase in the circulatory level of soluble angiogenesis factors and enhancement of microvasculature/microcirculation, resulting in an improvement of LVEF $[11,12]$. In the present study, circulating angiogenesis factors, such as VEGF and HGF, were also notably higher in the responders than in the non-responders (refer to Supplemental Table 1). Accordingly, our findings were consistent with those of our previous studies $[11,12]$.

SDF- $1 \alpha$, a chemokine protein of CXCL12, not only plays a beneficial role in the mobilization of EPCs from the bone marrow to circulation and homing of EPC to the ischemic area for angiogenesis through CXCR4dependent mechanism [28, 29], but also is associated with an increased risk of CAD via leukocyte activation and proinflammatory stimulation [30]. An interesting finding of ELISA in the present study was that the levels of SDF- $1 \alpha$ in the circulation and coronary sinus at different time points were consistently and notably lower in the responders than in the non-responders (refer to Supplemental Table 1), suggesting the non-responders presented with more severe coronary lesions (i.e., higher rates of old MI, CABG history, left main involvement and CTO at LAD shown in Table 1) and a more dominant intrinsic response to ischemic stimulation (i.e., higher levels of SDF-1 $\alpha$ ) than the responders.

Regrettably, this study did not measure the circulatory level of thrombospondin-1 (TSP1), a natural inhibitor of neovascularization, notably increased in the plateletpoor plasma of aged adults, and those with cardiovascular and metabolic disease [31]. Additionally, TSP1 has been identified to inhibit endothelial function, stimulates apoptosis, and suppresses nitric oxide, vascular endothelial growth factor, and the pluripotent transcription factors Oct3/4, Sox2, Klf4, and cMyc signaling [32]. These aforementioned issues raise the hypothesis that the low circulatory TSP1 level, perhaps, could be an extremely useful biomarker for predictive of responder and good outcome in our study.

The other interesting finding of the present study was former smokers closely linked to a good responder of stem cell therapy in the EnD-CAD patients. This association was compatible with the previous misleading phenomenon of "smoker's paradox" [33, 34], indicating 
Table 4 Early predictors of "good responder" after receiving G-CSF injection or stem cell therapy

\begin{tabular}{|c|c|c|c|c|c|c|}
\hline \multirow{2}{*}{$\begin{array}{l}\text { LVEF improvement } \geq 7.0 \% \\
\text { Variables }\end{array}$} & \multicolumn{3}{|c|}{ Univariate analysis } & \multicolumn{3}{|c|}{ Multivariate analysis } \\
\hline & OR & $95 \% \mathrm{Cl}$ & $P$ value & OR & $95 \% \mathrm{Cl}$ & $P$ value \\
\hline \multicolumn{7}{|l|}{ Baseline characteristics } \\
\hline Male sex & 0.301 & $0.082-1.106$ & 0.071 & 0.014 & $0.001-0.182$ & 0.001 \\
\hline Former smoker & 2.857 & $1.024-7.970$ & 0.045 & 11.032 & $2.028-60.004$ & 0.005 \\
\hline CCS angina score $\geq 3$ & 0.232 & $0.082-0.658$ & 0.006 & 0.092 & $0.019-0.449$ & 0.003 \\
\hline Grade 2 or 3 diast. Dysfxn & 0.240 & $0.081-0.710$ & 0.010 & 0.075 & $0.012-0.477$ & 0.006 \\
\hline \multicolumn{7}{|l|}{ Post G-CSF biomarkers } \\
\hline Post G-CSF leukocyte count, $\mu \mathrm{L}$ & 0.952 & $0.905-1.002$ & 0.058 & n/a & n/a & 0.906 \\
\hline Post G-CSF HPC count, $\mu \mathrm{L}$ & 0.987 & $0.972-1.002$ & 0.080 & $n / a$ & $\mathrm{n} / \mathrm{a}$ & 0.208 \\
\hline Post G-CSF young cell count & 0.992 & $0.900-1.093$ & 0.869 & & & \\
\hline Post G-CSF neutrophil count & 0.953 & $0.901-1.009$ & 0.097 & 0.905 & $0.831-0.986$ & 0.022 \\
\hline Flow data: stem cell, \% & 0.155 & $0.014-1.702$ & 0.127 & & & \\
\hline Performance CV, \% & 0.943 & $0.783-1.135$ & 0.533 & & & \\
\hline CD34+ cell, 1000/uL & 0.350 & $0.111-1.098$ & 0.072 & & & \\
\hline CD45+ cell, 1000/uL & 0.992 & $0.984-1.001$ & 0.068 & & & \\
\hline Troponin-l after cell therapy & 0.962 & $0.816-1.134$ & 0.641 & & & \\
\hline \multicolumn{7}{|l|}{ Biomarkers on ELISA } \\
\hline VEGF after G-CSF & 1.002 & $1.000-1.004$ & 0.082 & & & \\
\hline ANP-1 after G-CSF & 1.003 & $0.997-1.009$ & 0.352 & & & \\
\hline EGF after G-CSF & 0.996 & $0.991-1.001$ & 0.137 & & & \\
\hline HGF after G-CSF & 1.000 & $1.000-1.000$ & 0.462 & & & \\
\hline TGF- $\beta 1$ after G-CSF & 0.986 & $0.956-1.016$ & 0.359 & & & \\
\hline SDF-1a after G-CSF & 1.000 & $1.000-1.000$ & 0.123 & & & \\
\hline SDF-1a before SCT & 1.000 & $0.999-1.000$ & 0.057 & & & \\
\hline \multicolumn{7}{|c|}{ Change of Matrigel assay before and after G-CSF injection } \\
\hline Total tube length & 1.000 & $0.999-1.000$ & 0.118 & & & \\
\hline Mean tube length & 0.990 & $0.978-1.003$ & 0.125 & & & \\
\hline Number of tube formation & 0.969 & $0.905-1.037$ & 0.363 & & & \\
\hline Number of cluster formation & 1.054 & $0.978-1.137$ & 0.167 & & & \\
\hline Number of network formation & 0.893 & $0.771-1.035$ & 0.132 & & & \\
\hline
\end{tabular}

Notes: Abbreviation: G-CSF granulocyte-colony stimulating factor, $L V E F$ left ventricular ejection fraction, $O R$ odds ratio, $C I$ confidence interval, $n / a$ not applicable, $M I$ myocardial infarction, CCS Canadian Cardiovascular Society, diast. dysfxn diastolic dysfunction, WBC white blood cell, HPC hematopoietic progenitor cell, CV coefficient of variability, ELISA The enzyme-linked immunosorbent assay, VEGF vascular endothelial growth factor, ANP atrial natriuretic peptide, EGF epidermal growth factor, HGF hepatocyte growth factor, TGF- $\beta 1$ transforming growth factor beta 1, SDF-1a Stromal cell-derived factor-1 alpha, SCT stem cell therapy

better clinical outcomes were observed among the smokers suffering from acute myocardial infarction. Recent clinical researches $[35,36]$ have debunked that bizarre "smoker's paradox" was mainly affected by age factor because the majority of smokers presenting to the hospital were 10 years younger than nonsmokers. In addition, further analysis in our study revealed that the former smokers not only were younger, taller, and heavier but also had better eGFR and less history of CABG (refer to Supplemental Table 2). As a result, our findings and recent deep investigations could be explained, at least in part, for the close relationship of "former smoker" to "good responder" of cell therapy.
In the current study, $20 \%$ of patients in both groups suffered from acute decompensated HF with a need for hospitalization for further management. If there had been no evidence of myocardial injury, i.e., an elevated level of cardiac troponin-I, the patient was discharged without CAG after HF symptoms were improved. Otherwise, those with elevated troponin-I would undergo CAG and receive bailout coronary stenting at culprit lesion to increase myocardial perfusion. By the 9th month, all study subjects received follow-up CAG for the assessment of angiogenesis. Majority of patients in both groups underwent diagnostic CAG only. However, if the coronary flow had been limited by critical or progressive 
stenotic lesions as compared with baseline CAG findings as well as the vessel larger and suitable for intervention after cell therapy, myocardial revascularization with PCI would be performed as a bailout therapeutic strategy.

This study has limitations. First, despite the four variables were identified to be strongly predictive of either good responder or non-responder in the present study, these variables were not valid factors predictive of 1-year untoward clinical outcomes (refer to Supplemental Table 3) after CD34+ cell therapy. A prospective study to test predictors of good outcomes such as longer survival or better functional/echocardiographic improvement is encouraged. However, there are still several issues to be addressed in a prospective case-control study that will be conducted, e.g., difficulty in patient's enrollment and high event rate in such high-risk EnDCAD patients. Maybe, a retrospective study with a longer follow-up period or increase in study case number would be a better solution to answer the question. At that time, we will be able to apply cell-based therapy in highly selected patients or specific patient population with cost-effectiveness. Second, the long-term clinical follow-up (i.e., more than 1 to 5 years follow-up) is continuously conducted in phase II clinical trial. Accordingly, whether the currently identified variables will be able to predict 5-year "good responder" or "non-responder" remains to be answered.

\section{Conclusions}

The results of this study identified four baseline variables for the prediction of good responders prior to CD34+ therapy for the patients with EnD-CAD. These findings may provide essential and useful information on screening suitable candidates in a clinical cell-based research.

\section{Supplementary information}

Supplementary information accompanies this paper at https://doi.org/10. 1186/s13287-020-01835-z.

Additional file 1 : Table S1. Angiogenesis, biomarkers, and cell migration function before and after stem cell therapy.

Additional file $\mathbf{2}$ : Table S2. Variables of interest compared between smokers versus non-smokers.

Additional file $\mathbf{3}$ : Table $\mathbf{5 3}$. To test whether the new 4 identified factors can be used to predict adverse clinical events.

\footnotetext{
Abbreviations

PCl: Percutaneous coronary intervention; CABG: Coronary artery bypass grafting surgery; CAD: Coronary artery disease; EnD-CAD: End-stage diffuse coronary artery disease; EPC: Endothelial progenitor cell; MSC: Mesenchyma stem cell; LV: Left ventricular; LVEF: Left ventricular ejection fraction; GCSF: Granulocyte-colony stimulating factor; $\mathrm{H}$-L test: Hosmer-Lemeshow test; CTO: Chronic total occlusion; LAD: Left anterior descending; MI: Myocardial infarction; eGFR: Estimated glomerulus filtration rate; CCS: Canadian Cardiovascular Society; VEGF: Vascular endothelial growth factor; HGF: Hepatocyte growth factor; SDF-1a: Stromal cell-derived factor-1 alpha; ANP: Atrial natriuretic peptide; EGF: Epidermal growth factor;
}

TGF: Transforming growth factor; ELISA: The enzyme-linked immunosorbent assay

\section{Acknowledgements \\ None.}

\section{Authors' contributions}

PHS, MSL, and HKY designed the study and performed a catheterization procedure for cell delivery. $\mathrm{HJC}, \mathrm{YCL}, \mathrm{PLS}$, and FYL gathered the data and recorded clinical events. YCL and PLS prepared cell products and did bench work. PHS, HJC, CHC, and HKY analyzed and interpreted the data. PHS and HKY wrote the manuscript. The authors read and approved the final manuscript.

\section{Funding}

This study grant was funded by a program grant from the National Science Council, Taiwan, Republic of China (Grant number: 100-2314-B-182A-077 for the phase I trial; NMRPG8C0291, NMRPG8E0011, and NMRPG8F0011 for the phase II trial). It was also supported by a grant from Chang Gung Memorial Hospital, Chang Gung University (Grant number: CMRPG8B0901 and CMRP G8B0902 for the phase I trial).

\section{Availability of data and materials}

The datasets generated and analyzed are not publicly available due to consideration of patient privacy, but are available from the corresponding author on reasonable request for academic purpose.

\section{Ethics approval and consent to participate}

Ethics approval for this study was obtained from the Institutional Review Committee on Human Research at Chang Gung Memorial Hospital. All study subjects were informed about the study design and provided their informed consent.

Consent for publication

All patients signed a consent for use of their research data and publication.

\section{Competing interests}

The authors declare no competing interests.

\section{Author details}

${ }^{1}$ Division of Cardiology, Department of Internal Medicine, College of Medicine, Kaohsiung Chang Gung Memorial Hospital and Chang Gung University, No. 123, Ta Pei Road, Niao Sung District, Kaohsiung 83301, Taiwan. ${ }^{2}$ Center for Shockwave Medicine and Tissue Engineering, Kaohsiung Chang Gung Memorial Hospital, Kaohsiung 83301, Taiwan. ${ }^{3}$ Department of Obstetrics and Gynecology, College of Medicine, Kaohsiung Chang Gung Memorial Hospital and Chang Gung University, Kaohsiung 83301, Taiwan. ${ }^{4}$ Chung Shan Medical University School of Medicine, Taichung 40201 , Taiwan. ${ }^{5}$ Department of Computer Science and Engineering, National Sun Yat-sen University, Kaohsiung 80424, Taiwan. ${ }^{6}$ Department of Healthcare Administration and Medical Informatics, Kaohsiung Medical University, Kaohsiung 80708, Taiwan. 7 Department of Statistics, National Cheng Kung University, Tainan 70101, Taiwan. ${ }^{8}$ Institute of Statistics, National University of Kaohsiung, Kaohsiung 80708, Taiwan. ${ }^{9}$ Department of Nursing, Asia University, Taichung 41354, Taiwan. ${ }^{10}$ Division of Thoracic and Cardiovascular Surgery, Department of Surgery, Kaohsiung Chang Gung Memorial Hospital and Chang Gung University College of Medicine, Kaohsiung 83301, Taiwan.

${ }^{11}$ Division of Cardiovascular Surgery, Department of Surgery, Tri-Service General Hospital, National Defense Medical Center, Taipei 11490, Taiwan. ${ }^{12}$ Department of Orthopedics, College of Medicine, Kaohsiung Chang Gung Memorial Hospital and Chang Gung University, Kaohsiung 83301, Taiwan.

${ }^{13}$ Institute for Translational Research in Biomedicine, College of Medicine, Kaohsiung Chang Gung Memorial Hospital and Chang Gung University, Kaohsiung 83301, Taiwan. ${ }^{14}$ Department of Medical Research, China Medical University Hospital, China Medical University, Taichung 40402, Taiwan.

${ }^{15}$ Division of Cardiology, Department of Internal Medicine, Xiamen Chang

Gung Memorial Hospital, Xiamen 361028, Fujian, China. 
Received: 11 June 2020 Revised: 8 July 2020

Accepted: 15 July 2020 Published online: 29 July 2020

\section{References}

1. Held C, Asenblad N, Bassand JP, Becker RC, Cannon CP, Claeys MJ, et al. Ticagrelor versus clopidogrel in patients with acute coronary syndromes undergoing coronary artery bypass surgery: results from the PLATO (Platelet Inhibition and Patient Outcomes) trial. J Am Coll Cardiol. 2011;57(6):672-84.

2. Yasuda S, Kaikita K, Ogawa H, Akao M, Ako J, Matoba T, et al. Atrial fibrillation and ischemic events with rivaroxaban in patients with stable coronary artery disease (AFIRE): protocol for a multicenter, prospective, randomized, open-label, parallel group study. Int J Cardiol. 2018;265:108-12.

3. Ho YC, Tsai TH, Sung PH, Chen YL, Chung SY, Yang CH, et al. Minimizing door-to-balloon time is not the most critical factor in improving clinical outcome of ST-elevation myocardial infarction patients undergoing primary percutaneous coronary intervention. Crit Care Med. 2014;42(8):1788-96.

4. Sung PH, Wu CJ, Yip HK. Is extracorporeal membrane oxygenator a new weapon to improve prognosis in patients with profound cardiogenic shock undergoing primary percutaneous coronary intervention? Circ J. 2016;80(3): 572-8.

5. Liu H, Wilton SB, Southern DA, Knudtson ML, Maitland A, Hauer T, et al. Automated referral to cardiac rehabilitation after coronary artery bypass grafting is associated with modest improvement in program completion. Can J Cardiol. 2019;35(11):1491-8

6. Lin YS, Fang HY, Hussein H, Fang CY, Chen YL, Hsueh SK, et al. Predictors of contrast-induced nephropathy in chronic total occlusion percutaneous coronary intervention. Eurolntervention. 2014;9(10):1173-80.

7. Knuuti J, Wijns W, Saraste A, Capodanno D, Barbato E, Funck-Brentano C, et al. 2019 ESC guidelines for the diagnosis and management of chronic coronary syndromes. Eur Heart J. 2020;41(3):407-77.

8. Gegouskov V, Tochtermann U, Badowski-Zyla D, Thomas G, Hagl S, Osswald B. Long-term results after coronary artery reconstructive surgery. Thorac Cardiovasc Surg. 2007;55(5):293-7.

9. Jolicoeur EM, Cartier R, Henry TD, Barsness GW, Bourassa MG, McGillion M, et al. Patients with coronary artery disease unsuitable for revascularization: definition, general principles, and a classification. Can J Cardiol. 2012;28(2 Suppl):S50-9.

10. Henry TD, Satran D, Jolicoeur EM. Treatment of refractory angina in patients not suitable for revascularization. Nat Rev Cardiol. 2014;11(2):78-95.

11. Lee FY, Chen YL, Sung PH, Ma MC, Pei SN, Wu CJ, et al. Intracoronary transfusion of circulation-derived CD34+ cells improves left ventricular function in patients with end-stage diffuse coronary artery disease unsuitable for coronary intervention. Crit Care Med. 2015:43(10):2117-32.

12. Sung PH, Lee FY, Tong MS, Chiang JY, Pei SN, Ma MC, et al. The five-year clinical and angiographic follow-up outcomes of intracoronary transfusion of circulation-derived CD34+ cells for patients with end-stage diffuse coronary artery disease unsuitable for coronary intervention-phase I clinica trial. Crit Care Med. 2018;46(5):e411-8.

13. Losordo DW, Henry TD, Davidson C, Sup Lee J, Costa MA, Bass T, et al. Intramyocardial, autologous CD34+ cell therapy for refractory angina. Circ Res. 2011;109(4):428-36.

14. Dill T, Schachinger $\mathrm{V}$, Rolf $\mathrm{A}$, Mollmann $\mathrm{S}$, Thiele $\mathrm{H}$, Tillmanns $\mathrm{H}$, et al. Intracoronary administration of bone marrow-derived progenitor cells improves left ventricular function in patients at risk for adverse remodeling after acute ST-segment elevation myocardial infarction: results of the Reinfusion of Enriched Progenitor cells And Infarct Remodeling in Acute Myocardial Infarction study (REPAIR-AMI) cardiac magnetic resonance imaging substudy. Am Heart J. 2009;157(3):541-7.

15. Fisher SA, Doree C, Brunskill SJ, Mathur A, Martin-Rendon E. Bone marrow stem cell treatment for ischemic heart disease in patients with no option of revascularization: a systematic review and meta-analysis. PLoS One. 2013; 8(6):e64669.

16. Leu S, Sun CK, Sheu JJ, Chang LT, Yuen CM, Yen CH, et al. Autologous bone marrow cell implantation attenuates left ventricular remodeling and improves heart function in porcine myocardial infarction: an echocardiographic, six-month angiographic, and molecular-cellular study. Int J Cardiol. 2011;150(2):156-68.

17. Chen $\mathrm{KH}$, Chen $\mathrm{CH}$, Wallace $\mathrm{CG}$, Yuen $\mathrm{CM}$, Kao GS, Chen $\mathrm{YL}$, et al. Intravenous administration of xenogenic adipose-derived mesenchymal stem cells (ADMSC) and ADMSC-derived exosomes markedly reduced brain infarct volume and preserved neurological function in rat after acute ischemic stroke. Oncotarget. 2016;7(46):74537-56.

18. Quyyumi AA, Vasquez A, Kereiakes DJ, Klapholz M, Schaer GL, Abdel-Latif A, et al. PreSERVE-AMI: a randomized, double-blind, placebo-controlled clinical trial of intracoronary administration of autologous CD34+ cells in patients with left ventricular dysfunction post STEMI. Circ Res. 2017;120(2):324-31.

19. Bravery CA, Carmen J, Fong T, Oprea W, Hoogendoorn KH, Woda J, et al. Potency assay development for cellular therapy products: an ISCT review of the requirements and experiences in the industry. Cytotherapy. 2013;15(1):9-19.

20. Porat Y, Abraham E, Karnieli O, Nahum S, Woda J, Zylberberg C. Critical elements in the development of cell therapy potency assays for ischemic conditions. Cytotherapy. 2015;17(7):817-31.

21. Sung PH, Li YC, Lee MS, Hsiao HY, Ma MC, Pei SN, et al. Intracoronary injection of autologous CD34+ cells improves one-year left ventricular systolic function in patients with diffuse coronary artery disease and preserved cardiac performance-a randomized, open-label, controlled phase II clinical trial. J Clin Med. 2020;9(4):1043.

22. Wang S, Cui J, Peng W, Lu M. Intracoronary autologous CD34+ stem cell therapy for intractable angina. Cardiology. 2010;117(2):140-7.

23. Povsic TJ, Junge C, Nada A, Schatz RA, Harrington RA, Davidson CJ, et al. A phase 3, randomized, double-blinded, active-controlled, unblinded standard of care study assessing the efficacy and safety of intramyocardial autologous CD34+ cell administration in patients with refractory angina: design of the RENEW study. Am Heart J. 2013;165(6):854-61 e852.

24. Tsai T-H, Chai H-T, Sun C-K, Yen C-H, Leu S, Chen Y-L, et al. Obesity suppresses circulating level and function of endothelial progenitor cells and heart function. J Transl Med. 2012;10(1):1-12.

25. Pan T, Liu H, Fang Y, Wei Z, Gu S, Fang G, et al. Predictors of responders to mononuclear stem cell-based therapeutic angiogenesis for no-option critical limb ischemia. Stem Cell Res Ther. 2019;10(1):15.

26. Bredy C, Ministeri M, Kempny A, Alonso-Gonzalez R, Swan L, Uebing A, et al. New York Heart Association (NYHA) classification in adults with congenital heart disease: relation to objective measures of exercise and outcome. Eur Heart J. 2018;4(1):51-8.

27. Caraballo C, Desai NR, Mulder H, Alhanti B, Wilson FP, Fiuzat M, et al. Clinical implications of the New York Heart Association Classification. J Am Heart Assoc. 2019:8(23):e014240.

28. Yeh KH, Sheu JJ, Lin YC, Sun CK, Chang LT, Kao YH, et al. Benefit of combined extracorporeal shock wave and bone marrow-derived endothelial progenitor cells in protection against critical limb ischemia in rats. Crit Care Med. 2012;40(1):169-77.

29. Leu S, Lu HI, Sun CK, Sheu JJ, Chen YL, Tsai TH, et al. Retention of endothelial progenitor cells in bone marrow in a murine model of endogenous tissue plasminogen activator (tPA) deficiency in response to critical limb ischemia. Int J Cardiol. 2014;170(3):394-405.

30. Mega JL, Stitziel NO, Smith JG, Chasman DI, Caulfield M, Devlin JJ, et al. Genetic risk, coronary heart disease events, and the clinical benefit of statin therapy: an analysis of primary and secondary prevention trials. Lancet. 2015;385(9984):2264-71.

31. Isenberg JS, Roberts DD. Thrombospondin-1 in maladaptive aging responses: a concept whose time has come. Am J Physiol Cell Physiol. 2020; 319(1):C45-63.

32. Bornstein P. Thrombospondins function as regulators of angiogenesis. J Cell Commun Signal. 2009:3(3-4):189-200.

33. Kunz F, Pechlaner $C$, Hortnagl H, Pfister R. The smoker's paradox and the real risk of smoking. Eur J Epidemiol. 2005;20(2):161-7.

34. Venkatason P, Salleh NM, Zubairi Y, Hafidz I, Ahmad WA, Han SK, et al. The bizzare phenomenon of smokers' paradox in the immediate outcome post acute myocardial infarction: an insight into the Malaysian National Cardiovascular Database-Acute Coronary Syndrome (NCVD-ACS) registry year 2006-2013. Springerplus. 2016:5:534.

35. Redfors B, Furer A, Selker HP, Thiele H, Patel MR, Chen S, et al. Effect of smoking on outcomes of primary PCl in patients with STEMI. J Am Coll Cardiol. 2020:75(15):1743-54.

36. White HD. Deconstructing the paradox of smoking and improved shortterm cardiovascular outcomes after myocardial infarction. J Am Coll Cardiol. 2020;75(15):1755-7.

\section{Publisher's Note}

Springer Nature remains neutral with regard to jurisdictional claims in published maps and institutional affiliations. 